\title{
AN ALGORITHM FOR COASTLINE DETECTION USING SAR IMAGES
}

\author{
U. Acar ${ }^{\text {a }}$, B. Bayram ${ }^{\text {a }}$, F. Balik Sanli ${ }^{\text {a }}$, S.Abdikan ${ }^{\text {a, }}$ F. Sunar ${ }^{\text {b }}$ H. I. Cetin ${ }^{\text {a }}$, \\ ${ }^{a}$ YTU, Civil Engineering Faculty, 34220 Esenler Istanbul, Turkey - (uacar, bayram, fbalik, sabdikan, \\ içetin)@yildiz.edu.tr \\ b ITU, Civil Engineering Faculty, 80626 Maslak Istanbul, Turkey - fsunar@itu.edu.tr
}

\section{ICWG III/VII}

KEY WORDS: Coastline extraction, remote sensing, image processing, SAR, PALSAR

\begin{abstract}
:
Coastal management requires rapid, up-to-date, and correct information. Thus, coastal movements have primary importance for coastal managers. For monitoring the change of shorelines, remote sensing data are some of the most important information and are utilized for differentiating any detections of change on shorelines. It is possible to monitor coastal changes by extracting the coastline from satellite images. In the literature most of the algorithms developed for optical images have been discussed in detail. In this study, an algorithm which extracts coastlines efficiently and automatically by processing SAR (Synthetic Aperture Radar) satellite images has been developed. A data set of ALOS Palsar image of Fine Beam Double (FBD) HH-HV polarized data has been used. PALSAR image has L-band data, and has a $14 \mathrm{MHz}$ bandwidth and 34.3 degrees look angle. Data were acquired in ascending geometry. Ground resolution of PALSAR image was resampled to $15 \mathrm{~m}$ to amplitude image. Zonguldak city, lies on the northwest costs of Turkey, has been selected as the test area. An algorithm was developed for automatic coastline extraction from SAR images. The algorithm is encoded in a C__ environment. To verify the results the algorithm was applied on two PALSAR images gathered in two different date as 2007 and 2010. The results of automatic coastline extraction obtained from SAR images were compared to the results derived from manual digitizing. Random control points which are seen on each image were used. The average differences of selected points were calculated.
\end{abstract}

\section{INTRODUCTION}

As a peninsula country Turkey has a coastline more over than $8300 \mathrm{~km}$, and $1700 \mathrm{~km}$ of this is surrounded by Black Sea. For the study area coastline detection is important because this region has mining which are located at the coast and has international ports. Due to fact that it is needed to update coastline information and morphological changes versus any natural disaster. Since this area suffer from flooding and erosion problems. It is crucial to have rapid and updatable output for decision makers in coastal management.

Remote sensing data provide large scale surfaces to extract changes of features. Satellite images are widely used to extract coastline with both optical and SAR data. Wang et al (2010) presented a class association rule algorithm and designed a method to separate land and sea from each other. Karsli et al (2011) developed a thresholding method using top of atmosphere reflectance and normalized difference water index (NDWI) of Landsat image. Moreover, ISODATA classification method is used to observe long term shoreline changes ( $\mathrm{Yu}$, et al, 2011). He indicated the significance of using archived data for the effective assessment of coastline changes.

Wavelet based edge detection method is used for coastline detection from ERS data by Niedermeier, et al. (2000). Liu and Jezek, 2004, used thresholding technique on Landsat and Radarsat data. Wang and Ellen (2008) calculated the backscatter coefficient $(\mathrm{dB})$ values of $\mathrm{HH}$ polarized L-band SAR data and applied an edge-filtering model with Sobel filter. Two enhanced Level Set Algorithm (LSA) which is based on active contours or snakes are applied on Radarsat imagery by Ouyang et al (2010). Another wavelet based edge detection algorithm is developed for coastal change detection from ERS data by Chen et al.
(2011), and morphological filter is followed to refine the boundaries.

In this study we improved an automatic coastline extraction algorithm to extract coastline feature from ALOS/PALSAR data. The algorithm was successfully applied on optical data such as CORINA, IRS-1D and Landsat in previous study (Bayram et al., 2008).

\section{STUDY AREA}

The study area covers the Zonguldak and Bartin cities which are located at the coastline of the Black Sea in the north-west part of Turkey. The adjacent provinces of the study are located as Kastamonu at the east, Karabuk and Bolu at the south and Duzce at the southwest. In the area there are two main streams which drain water to the Black Sea. Bartın stream is drains at the coast of Bartın and Filyos stream drain in Caycuma city of Zonguldak (Figure 1).

In these cities the main economic support is underground coal mining. It is the biggest and only hard coal mining in Turkey. Also industrial raw materials such as limestone, marble, quartzite are the main products of the study area.

An oceanic (maritime) climate is dominant in Zonguldak, and precipitation is distributed almost evenly during the whole year. The mean humidity reaches up to $\% 70$. Along the coastline mountain align parallel to the coast. The area has a rough topography which rates up to $1000 \mathrm{~m}$. 


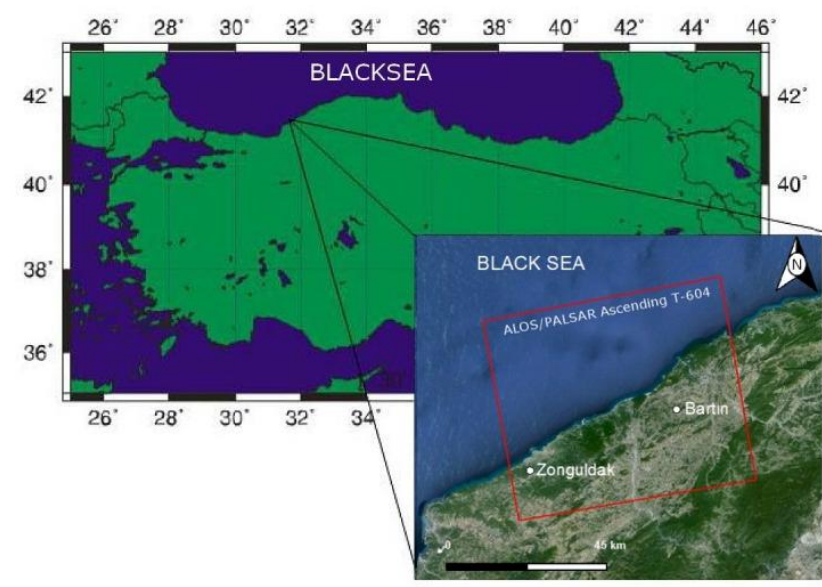

Figure 1. Study area

\section{STUDY AREA}

\section{Materials}

We used Advanced Land Observing Satellite (ALOS) Phased Array type L-band Synthetic Aperture Radar (PALSAR) data for the coastline detection. SAR data gathered in raw format and first converted to a Single Look Complex (SLC) data then converted to a 4 multi-look data. Fine Beam Dual (FBD) mode $\mathrm{HH}$ and $\mathrm{HV}$ polarized ALOS data has a $14 \mathrm{MHz}$ bandwidth and 34.3 degrees look angle. PALSAR which uses L-band to illuminate the Earth surface is acquired in ascending geometry, and the ground resolution of the amplitude images are resampled to $15 \mathrm{~m}$.

In the process to indicate the effect of polarization $\mathrm{HH}$ and $\mathrm{HV}$ polarized images processed with the algorithm separately and compared. To verify the results two dated 2007 and 2010 PALSAR images are acquired and the algorithm was applied on four images in total.

\begin{tabular}{|c|c|c|c|c|c|c|}
\hline Sensor & $\begin{array}{c}\text { Swath } \\
\text { km }\end{array}$ & Pass & $\begin{array}{c}\text { Trac } \\
\text { k No }\end{array}$ & $\begin{array}{c}\text { Frame } \\
\text { No }\end{array}$ & Pol & Date \\
\hline $\begin{array}{c}\text { Alos- } \\
\text { Palsar }\end{array}$ & 70 & Asc. & 604 & 820 & HH & $\begin{array}{c}05-09- \\
2007\end{array}$ \\
\hline $\begin{array}{c}\text { Alos- } \\
\text { Palsar }\end{array}$ & 70 & Asc. & 604 & 820 & HV & $\begin{array}{c}13-06- \\
2010\end{array}$ \\
\hline
\end{tabular}

Table 1. Specifications of ALOS data

\section{METHODOLOGY}

In this study, the radiometric resolution of both SAR images is 32 bit. As the image histogram describes the statistical distribution of the image pixels in terms of the number of pixel at each DN, both image scenes of the study area have bimodel histogram which indicates two dominant materials as water and land in the area. In the process of land (i.e. coast) and water separation, the radiometric resolution of the images was reduced to 8 bit in order to decouple noise from image as well as to increase the processing speed (Figure 2). In the last step of the process the final images were converted to binary images.

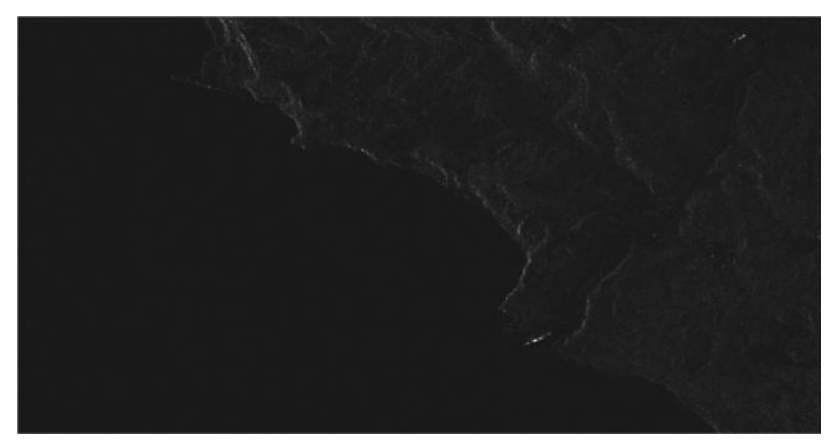

Figure 2 Part of the image scene which was reduced to 8-bit radiometric resolution

For the purpose of making more apparent the sharp radiometric difference between the coast (land) and sea, histogram equalization process was applied on the images (Figure 3).

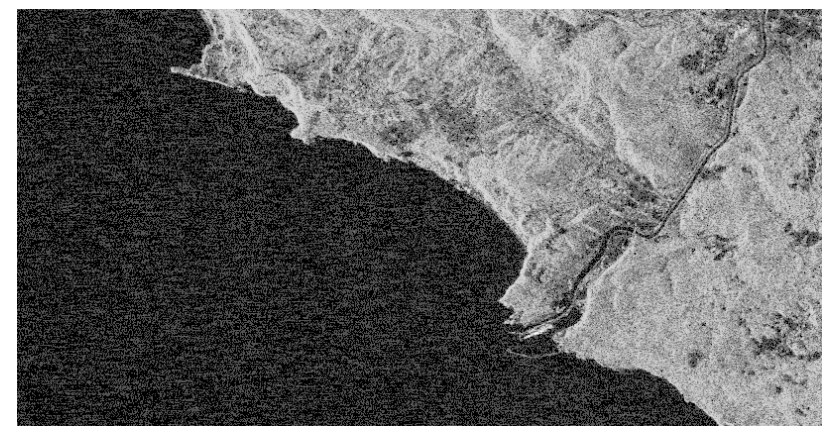

Figure 3. Histogram equalization applied image part.

Two types of images came out after the histogram equalization process. These two types were described as "too noisy" and "less noisy" image. Since the amount of the noise affect the extraction of coastline, various algorithms needed to be applied. In order to describe image as too noisy or less noisy, land and water parts of the images were separated as the first step. For this purpose, a $100 \times 100$ search window was applied on the entire image scenes to split the completely land and completely water portion of the images. In this process 128 was selected as the threshold value for the windows of 10000 pixels. If the number of pixels with 0 (black) values was $\% 200$ greater than the number of pixels with 255 (white) values, then the pixel group was assigned as water (Figure 4). The percentage value (\% 200) was defined empirically.

In all images a large portion of all the noise was found to have the same gray value. One more check was done on each window assigned as water. A check was carried out on the histograms of the every $100 \times 100$ search window, and the gray values with maximum number of pixel except for zeros were assigned as noise (Figure 4). 


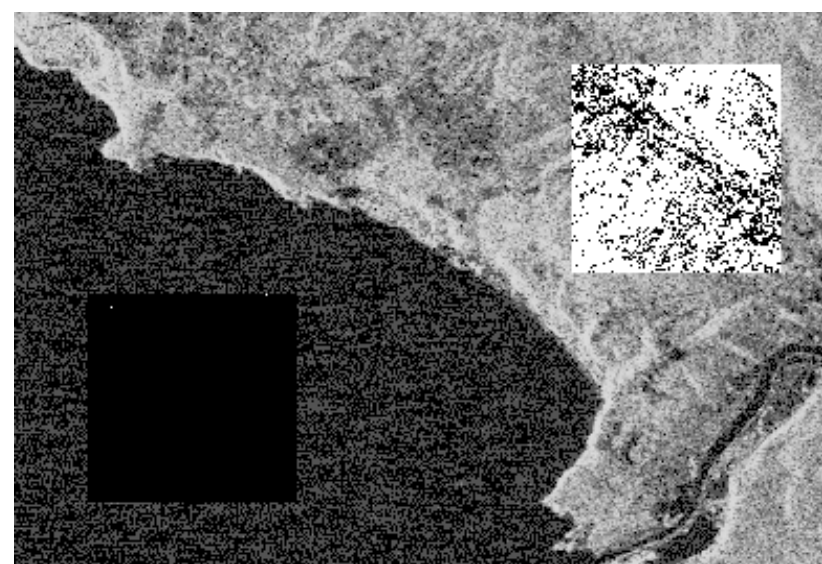

Figure 4. Defining threshold value for land and sea part of the images using 100x 100 search window.

As seen from the histogram, in the area consisting of 10000 pixels, the gray value of 4477 pixels was 105 , the gray value of 5461 pixels was 0 , and the gray values of 162 pixels was 141 (Figure 5). Hence gray value of noise was assigned as 105. If the number of noise pixel was \% 30 graters then the number of 0 pixels then the image is accepted as noisy. If the image was too noisy, than the gray values of noisy pixels were removed. If the image was less noisy than next step was processed.

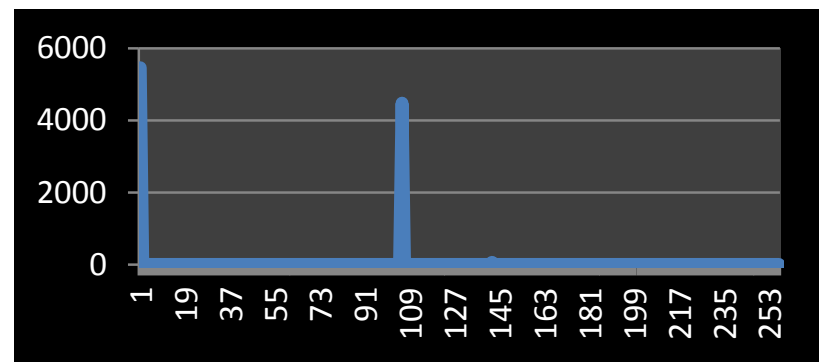

Figure 5. A Histogram consisting of 100x100 pixels from the sea part of the image.

After the elimination of pixels having regular noise value in the image scene, a mathematical morphology was used to eliminate pixels having random noise value (Acar, U., 2011). In the water part of the image, in order to remove the gray values of noise pixels by the dominant 0 (zero) pixel values a $3 \times 3$ circle structuring element was used. The reason preferring the $3 \times 3$ circle structuring element is that the area of noise pixels was not greater than 1 pixel, and mathematical morphology applied with this structuring element was sufficient to eliminate the noise (Figure 6).

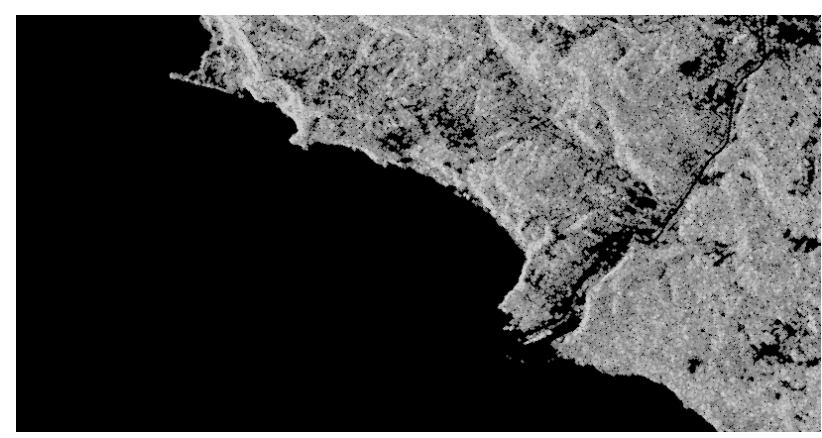

Figure 6. Mathematical morphology opening applied image.
The applied image processing techniques caused some gaps and distortions on coastline. In order to reduce this gap and corruption, again a mathematical morphology was applied as closing this time. In this process a $5 \times 5$ circle structuring element was preferred. The reason to prefer the $5 \times 5$ circle structuring elements is its ability to eliminate distortion and gaps up to 5 pixels. The larger circle structuring selection results in the loss of the small bays and recesses (Figure 7).

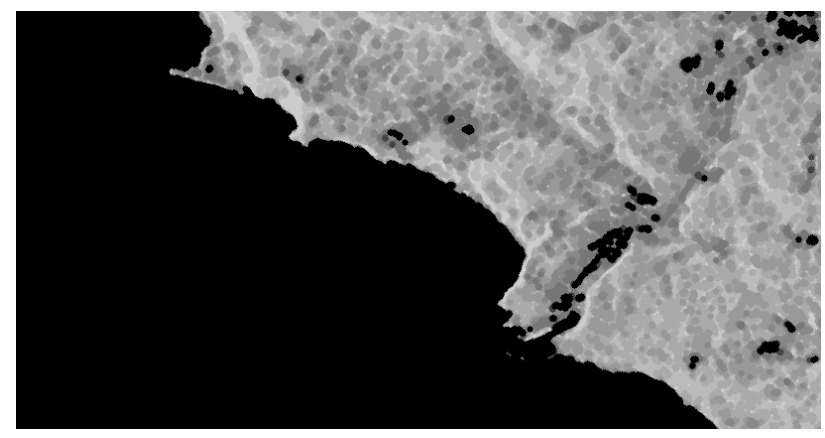

Figure 7. Mathematical morphology closing applied image

After mathematical morphology application, despite the possibility of remaining noise in the image, one more filter was applied. Task of this filter was to eliminate gray value of noise in a group of pixels when there were only zero gray values and noise gray values in that group of pixels (Figure 8).

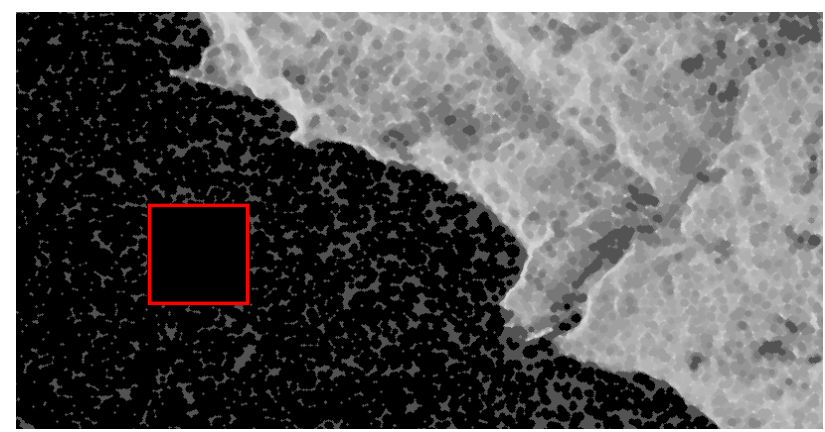

Figure 8. Eliminating remaining noise gray values.

For the resulting image a fit-coast algorithm (Bayram, B., 2008) was used (Figure 9). It is a region growing algorithm using image processing techniques.

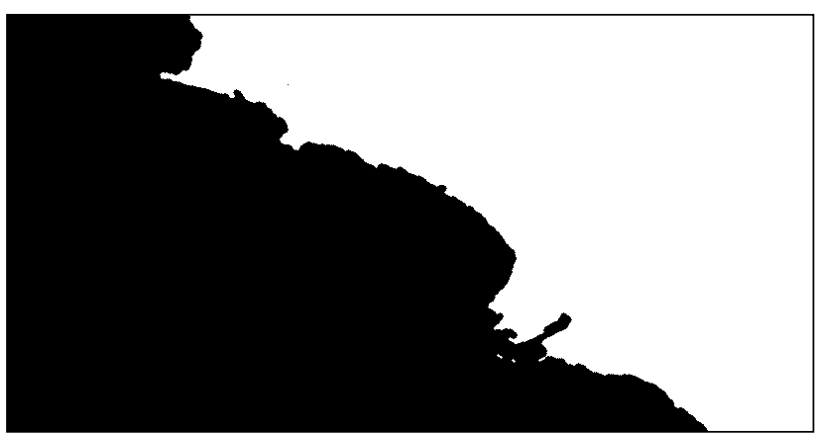

Figure 9. The result of Fit-Coast algorithm application

Sobel operator was applied on the binary image generated by fit-coast algorithm and then image was converted to vector data (Figure 10). 


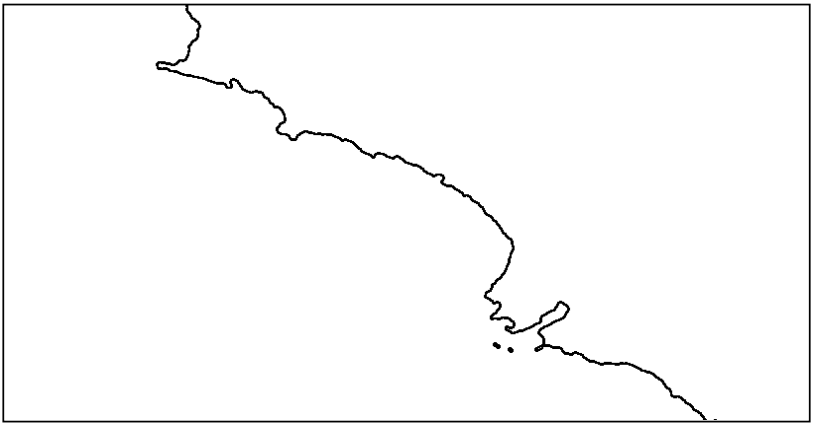

Figure10. Automated extorted coastline converted to vector data.

\section{RESULTS}

Since coastal management requires rapid, up-to-date, and correct information, coastal movements have primary importance for coastal managers. Remote sensing is an important technique for detecting and monitoring coastlines using satellite images. In the literature most of the algorithms developed for optical images have been discussed in detail. In this study the use of SAR images was investigated for automatic coastline detection by using PALSAR images.

The algorithm was applied on 4 images gathered in 2007 and 2010 in two polarizations as HH and HV. In order to test the accuracy of coastline detection, all images were digitized manually. To calculate the total difference between the automatic coastline detection and manually digitizing, land side of the each image was converted to a closed polygon and its area was calculated. Then the calculated areas of manual and automatic extractions were compared Table 2. Since digitizing coastline from PALSAR images is not an easy and simple task due to the feature of SAR images, for each pair the manual digitizing which was thought to be the best coastline extraction was chosen.

\begin{tabular}{|c|c|c|}
\hline Image & $\begin{array}{c}\text { Automatic } \\
\text { Digitalized(pixel) }\end{array}$ & $\begin{array}{c}\text { Manual } \\
\text { Digitalized (pixel) }\end{array}$ \\
\hline $2007 \mathrm{HV}$ & 315504 & \multirow{2}{*}{315693} \\
\hline $2007 \mathrm{HH}$ & 315804 & \multirow{2}{*}{316860} \\
\hline $2010 \mathrm{HV}$ & 316805 & 316887 \\
\hline $2010 \mathrm{HH}$ & \\
\hline
\end{tabular}

Table 2. Comparison between automatic coastline detection and manual digitizing.

Overall length of the coastline extracted automatically was compered with the manually digitized coastline (Table 3).For each image scene the difference is less than \%0.9.

\begin{tabular}{|c|c|c|c|}
\hline Image & $\begin{array}{c}\text { Manual } \\
\text { Digitalized } \\
\text { (pixel) }\end{array}$ & $\begin{array}{c}\text { Automatic } \\
\text { Digitalized } \\
\text { (pixel) }\end{array}$ & $\begin{array}{c}\text { Automatic } \\
\text { Digitalized } \\
\text { (Percent) }\end{array}$ \\
\cline { 1 - 3 } $2007 \mathrm{HV}$ & \multirow{2}{*}{24566} & 24716 & 0,61 \\
\hline $2007 \mathrm{HH}$ & 24355 & 0,85 \\
\hline $2010 \mathrm{HV}$ & \multirow{2}{*}{25003} & 24898 & 0,41 \\
\cline { 1 - 1 } $2010 \mathrm{HH}$ & & 25055 & 0,21 \\
\hline
\end{tabular}

Table 3. Comparison between the lengths of automatically extracted and manually digitized coastlines.

\section{REFERENCES}

Acar, U., 2011 Data Extraction With Similar Techniques: Satellite Images And Medical Phd. Thesis (In Turkish). YTU Istanbul Turkey.

Bayram, B., Acar, U., Seker, D., Ari, A., 2008. A novel algorithm for coastline fitting through a case study over the Bosphorus. Journal of Coastal Research, 24(4), 983-991.

Chen, K.S., Wang, H.W., Wang, C.T., Chang, W.Y., 2011, A Study of Decadal Coastal Changes on Western Taiwan Using a Time Series of ERS Satellite SAR Images, IEEE Journal of Selected Topics in Applied Earth Observations and Remote Sensing, 4(4), 826-835

Liu, H. and JEZEK, K.C., 2004. Automated extraction of coastline from satellite imagery by integrating Canny edge detection and locally adaptive thresholding methods. International Journal of Remote Sensing, 25(5), 937-958.

Niedermeier, A., Romaneessen, E. and Lehner, S., 2000, Detection of coastlines in SAR images using wavelet methods. IEEE Transactions on Geoscience and Remote Sensing, 38, pp. 2270-2281.

Karsli, F., Gunerioglu, A., Dihkan., M., 2011, Spatio temporal shoreline changes along the Black Sea coastal zone, Journal of Applied Remote Sensing, Vol-5, 2011.

Wang, Y., Allen, R. T., 2008, Estuarine shoreline change detection using Japanese ALOS PALSAR HH and JERS-1 LHH SAR data in the Albemarle-Pamlico Sounds, North Carolina, USA, International Journal of Remote Sensing, 29(15), 4429-4442.

Ouyang, Y., Chong, J., Wu, Y., 2010, Two coastline detection methods in Synthetic Aperture Radar imagery based on Level Set Algorithm, International Journal of Remote Sensing, 31 (1718), 4957-4968.

Wang, C., Zhang, J., Ma, Y., 2010, Coastline interpretation from multispectral remote sensing images using an association rule algorithm, International Journal of Remote Sensing, 31(24), 6409-6423

Yu, K., Hu, C., Muller-Karger, E.F., Lu, D., Soto, I., 2011, Shoreline changes in west-central Florida between 1987 and 2008 from Landsat observations, International Journal of Remote Sensing, 32 (23), 8299-8313 